\title{
A Preliminary Study on the Synthesis and Characterization of Multilayered Ag/Co Magnetic Nanowires Fabricated via the Electrodeposition Method
}

\author{
Cheng-Hsiung Peng, ${ }^{1}$ Tsung-Yung Wu, ${ }^{2}$ and Chyi-Ching Hwang ${ }^{3}$ \\ ${ }^{1}$ Department of Chemical and Materials Engineering, Ming Hsin University of Science and Technology, Hsinfeng, Hsinchu 304, Taiwan \\ ${ }^{2}$ School of Defense Science, Chung Cheng Institute Technology, National Defense University, Daxi, Taoyuan 335, Taiwan \\ ${ }^{3}$ Wapeon System Center, Chung Cheng Institute Technology, National Defense University, Daxi, Taoyuan 335, Taiwan \\ Correspondence should be addressed to Cheng-Hsiung Peng; chpeng@must.edu.tw
}

Received 1 July 2013; Accepted 31 July 2013

Academic Editors: C. W. Kan and C. Moura

Copyright (c) 2013 Cheng-Hsiung Peng et al. This is an open access article distributed under the Creative Commons Attribution License, which permits unrestricted use, distribution, and reproduction in any medium, provided the original work is properly cited.

A single-bath electrodeposition method was developed to integrate multilayer Ag/Co nanowires with a commercial anodic alumina oxide (AAO) template with a pore diameter of $100-200 \mathrm{~nm}$. An electrolyte system containing silver nitride and cobalt sulfide was studied using cyclic voltammetry, and the electrodeposition rate was varied to optimize the electrodeposition conditions. A constant stepwise potential and a variable cation ratio of $\left[\mathrm{Co}^{2+}\right] /\left[\mathrm{Ag}^{+}\right]$were used during electrodeposition. After the dissolution of the template in aqueous $\mathrm{NaOH}$ solution, multilayered $\mathrm{Ag} / \mathrm{Co}$ nanowires were obtained with a composition of $[\mathrm{Co}] /\left[\mathrm{Ag}_{80} \mathrm{Co}_{20}\right]$, as identified by XRD and TEM, when $\left[\mathrm{Co}^{2+}\right] /\left[\mathrm{Ag}^{+}\right]=150$. By annealing at $200^{\circ} \mathrm{C}$ for $1 \mathrm{~h}$, uniformly structured $\left(\mathrm{Co}_{99.57} / \mathrm{Ag}_{100}\right)$ nanowires were obtained. Compared with pure Co nanowires, the magnetic hysteresis loops showed a greater magnetic anisotropy for $\left(\mathrm{Co}_{99.57} / \mathrm{Ag}_{100}\right)$ nanowires than for pure Co nanowires, corresponding to a change in the easy axis upon magnetization.

\section{Introduction}

The synthesis and study of nanoscale materials have attracted much attention in recent years. One-dimensional nanostructures, including nanowires, nanorods, and nanotubes, have many amazing properties such as high density, high aspect ratio, and low threshold voltage in field emission. On the other hand, the application of the giant magnetoresistance (GMR) effect found in 2-D metallic multilayers [1] has also been rigorously investigated for applications in the magnetic industry such as information storage and magnetic sensors $[2,3]$. The development of high-density perpendicular magnetic recording encourages the trend to investigate new types of magnetic structures as the medium. With the combination of nanowires and multilayered structures, multilayered nanowires will exhibit special characteristics compared to conventional magnetic materials.

In general, a hard template containing nanometer-sized cylindrical pores is used as the membrane for the synthesis of magnetic nanowires and the pores are filled with segments of nanowires of different elements. Electrochemical synthesis utilizing the multibath or single-bath method is usually used to deposit the multimetal segments into the template for better efficiency and cheaper processing [4]. The most widely used templates for template-synthesized metallic nanowire arrays [5] are ion track-etched polycarbonate [6], anodic aluminum oxide (AAO) [7, 8], and mica [9]. Multibath electrodeposition was not considered in this research due to the difficulty of removing residual electrolyte containment from the nanometer channels $[10,11]$. Recently, some studies on magnetic multilayered nanowires, including $\mathrm{Co} / \mathrm{Cu}[12-$ 14], $\mathrm{Cu} / \mathrm{Ni}$ [15], $\mathrm{Au} / \mathrm{Co}$ [16], and Ag/Co [17], used the singlebath electrodeposition technique, where two types of metallic ions coexist in the electrolyte during the deposition.

Due to the immiscibility of $\mathrm{Ag}$ and $\mathrm{Co}$, an $\mathrm{Ag} / \mathrm{Co}$ multilayer structure $[18,19]$ should possess a more distinguished interface than other sets of multilayer magnets, and it might be applicable in high-density perpendicular magnetic 


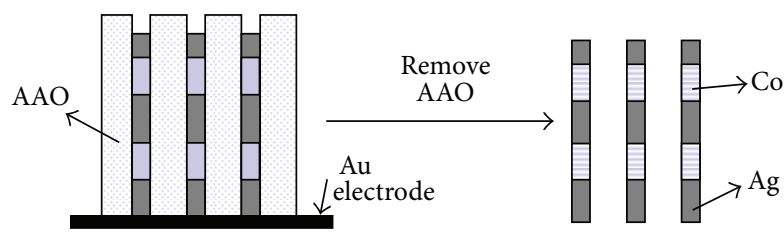

FIGURE 1: Multilayered nanowires structure.

recording media. Therefore, in this research, a new electrolyte combined with a stepped-potential controlled system was developed for the synthesis of $\mathrm{Ag} / \mathrm{Co}$ multilayered nanowires using the single-bath method. The electrochemical behavior and magnetic hysteresis of the nanowires are discussed below.

\section{Experimental Methods}

To obtain multilayer nanowires, it was necessary to electrodeposit the metal segments within the channels of the $\mathrm{AAO}$ in sequence. After dissolving the template in $\mathrm{NaOH}$, a multilayer structure was obtained, as shown schematically in Figure 1. Commercially available nanoporous alumina membranes (AAO) with a thickness of $60 \mu \mathrm{m}$ and a nominal pore diameter of $100 \mathrm{~nm}$ (actual range: $100 \mathrm{~nm} \sim 200 \mathrm{~nm}$ ) were used. The pore density of the AAO was $1 \times 10^{10}$, and the pore interdistance was approximately $50-70 \mathrm{~nm}$, which was confirmed by SEM analysis. The electrolyte used in the experiment contained $\mathrm{CH}_{3} \mathrm{COONH}_{4}, \mathrm{AgNO}_{3}$, and $\mathrm{CoSO}_{4} \cdot 7 \mathrm{H}_{2} \mathrm{O}$ developed by our group. The major reactions are listed below:

$$
\begin{aligned}
& \mathrm{Ag}=\mathrm{Ag}^{+}+\mathrm{e}^{-} \quad E=-0.799 \mathrm{~V} \\
& \mathrm{Co}=\mathrm{Co}^{2+}+2 \mathrm{e}^{-} \quad E=0.277 \mathrm{~V} .
\end{aligned}
$$

The solubility product of $\mathrm{Ag}\left(\mathrm{CH}_{3} \mathrm{COO}\right), K_{\mathrm{sp}}=2.3 \times$ $10^{-29}$, is much lower than that of $\mathrm{Ag}\left(\mathrm{NH}_{3}\right)^{2+}\left(K_{\text {sp }}=6.3 \times\right.$ $\left.10^{-8}\right)$, so the results of precipitation during the first few minutes were observed closely when the binary-electrolyte system was prepared in $\mathrm{CH}_{3} \mathrm{COONH}_{4}$. Finally, the formation of complex ion $\mathrm{Ag}\left(\mathrm{NH}_{3}\right)^{2+}$ gradually substituted $\mathrm{Ag}\left(\mathrm{CH}_{3} \mathrm{COO}\right)$ to form a clear electrolyte solution.

The oxidation potentials and electrodeposition rate can be altered by altering the ion concentrations, such as $\mathrm{Ag}^{+}$and $\mathrm{Co}^{2+}$, according to the Nernst equation and kinetic theory as follows:

$$
E=E^{0}-\frac{2.3 R T}{n F} \log Q
$$

where $Q$ is the reaction quotient, $R$ is the gas constant $\left(8.314 \mathrm{~J} \mathrm{~mol}^{-1} \mathrm{~K}^{-1}\right), n$ is mole number of electrons involved in the reaction, $F$ is the Faraday constant $\left(96485 \mathrm{C} \mathrm{mol}^{-1}\right)$, and $T$ is the temperature (in $\mathrm{K}$ ). The cyclic-voltammetry and competing rate analysis of $\mathrm{Ag} / \mathrm{Co}$ electrodeposition were used to refine and optimize the electrodeposition conditions for the single-bath electrodeposition. Cyclic-voltammetry was measured with a CHI 604A electrochemical analyzer (CH Instrument, USA) with a scanning rate of $0.1 \mathrm{~V} / \mathrm{sec}$. Glassy carbon and Pt wire were used as the working and

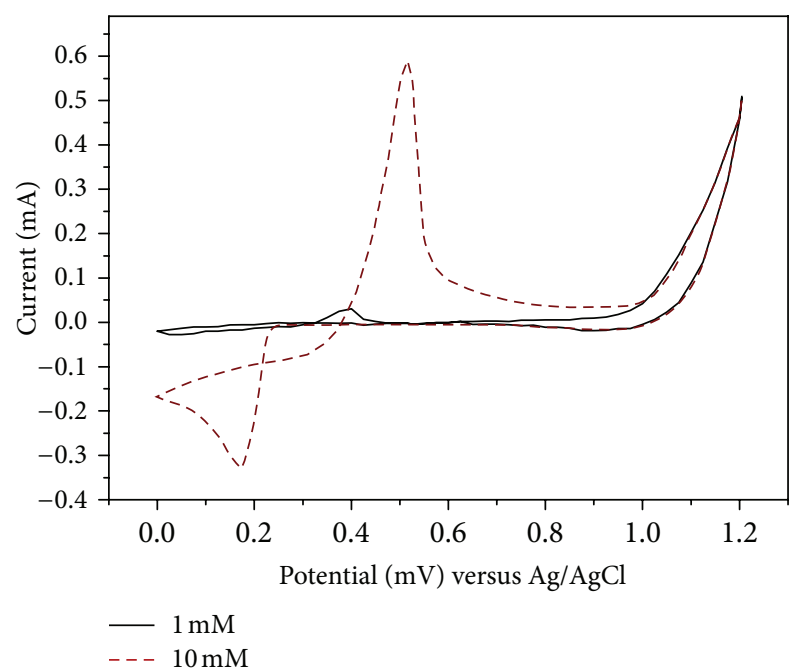

FIGURE 2: Cyclic-voltammetry analysis by altering $\left[\mathrm{Ag}^{+}\right]$with constant $\left[\mathrm{Co}^{2+}\right]=0.15 \mathrm{M}$.

counter electrodes, respectively, while $\mathrm{Ag} / \mathrm{AgCl}$ was used as the reference electrode.

A power supply, such as a source-meter (Keithly 2400, Keithly USA), was used to control the parameters of each step, including apply voltage, and deposition time, during the multi-step electrodeposition using a PC-based program. In addition to the step electrodeposition method, the characteristics of the potential segments were also varied, such as decreasing the segment time and off-potential time to overcome the charging problem. Anodic aluminum oxide (AAO) was used as the template for deposition to accommodate the post annealing process. A DC-sputtered gold layer with a thickness of approximately $200 \mathrm{~nm}$ was used as the conducting bottom layer of the AAO. For the convenience of characterization, the AAO membrane was dissolved in 5\% $\mathrm{NaOH}$ after electrodeposition. X-ray diffraction (XRD) and electron microscopy, such as field-emission scanning electron microscopy (FESEM) and transmission electron microscopy (TEM), were used to identify the compositions and structures of the nanowires. The magnetic behavior of the $\mathrm{Ag} / \mathrm{Co}$ multilayered nanowires within AAO was also investigated with a vibrating sample magnetometer VSM.

\section{Results and Analysis}

3.1. Electrochemical Analysis. Figure 2 shows the cyclicvoltammetry analysis by altering $\left[\mathrm{Ag}^{+}\right]$with constant $\left[\mathrm{Co}^{2+}\right]=0.15 \mathrm{M}$. It was observed that the concentration of $\left[\mathrm{Ag}^{+}\right]$played a more important role than that of $\left[\mathrm{Co}^{2+}\right]$. The difference in the electrodeposition rate at various voltages was examined by the energy-dispersive spectroscopy (EDS) analysis of the deposition layer, and the results are shown in Figure 3. With two different $\left[\mathrm{Ag}^{+}\right]$equal to $1 \mathrm{mM}$ and $10 \mathrm{mM}$, the deposition of the Co layer did not start until $0.7 \mathrm{~V}$, and the stacking rate of $\mathrm{Ag}$ and Co increased drastically with increasing voltage. When the applied voltage was high enough to force the reduction of $\mathrm{Co}^{2+}$ ions, the $\mathrm{Co} / \mathrm{Ag}$ ratio 


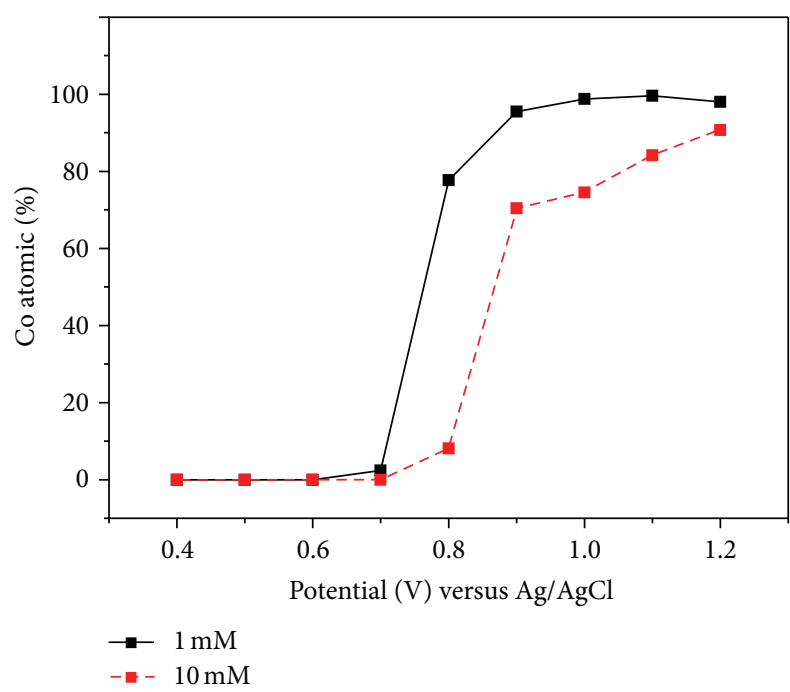

Figure 3: Electrodeposition rate upon altering $\left[\mathrm{Ag}^{+}\right]$with constant $\left[\mathrm{Co}^{2+}\right]=0.15 \mathrm{M}$.

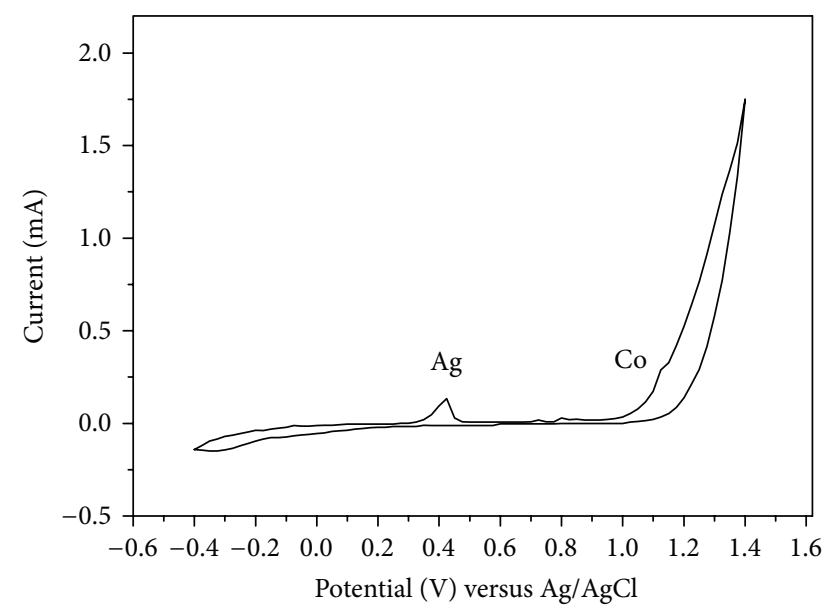

FIGURE 4: Cyclic-voltammetry analysis of the solution with $\left[\mathrm{Co}^{2+}\right] /$ $\left[\mathrm{Ag}^{+}\right]=150$.

increased. However, the electrolysis of water also occurred at a higher voltage to break the competition balance of the ions, and the effective current density decreased. Therefore, the reduction of the two metal ions decreased. As a result, a nearly pure Co layer $(\mathrm{Co}=98.83 \%, \mathrm{Ag}=1.07 \%)$ was produced when the applied voltage was $1.1 \mathrm{~V}$ versus $\mathrm{Ag} / \mathrm{AgCl}$ at the concentration ratio $\mathrm{Co} / \mathrm{Ag}=150$. In the cyclic-voltammetry analysis shown in Figure 4, the ion concentration ratio between $\left[\mathrm{Co}^{+}\right]$and $\left[\mathrm{Ag}^{2+}\right]$ was fixed at $\mathrm{Co} / \mathrm{Ag}=150$. It was observed that the reduction of $\mathrm{Ag}^{+}$began at about $0.3 \mathrm{~V}$ (versus $\mathrm{Ag} / \mathrm{AgCl}$ ), and Co did not begin to appear until $0.8 \mathrm{~V}$.

Although pure Ag segments could be obtained when the applied voltage was below $0.6 \mathrm{~V}$, the deposition rate was too slow to complete the experiments within an acceptable time. In addition, the reduction effect could also strongly dissolve the cobalt layer deposited previously. Therefore, two factors were considered in the design of the deposition sequence of
TABLE 1: Deposition parameters of Ag/Co multilayered nanowires.

\begin{tabular}{lccc}
\hline Ingredient & $\begin{array}{c}\text { Concentration } \\
(\mathrm{M})\end{array}$ & $\begin{array}{c}\text { Potential } \\
(\mathrm{V})\end{array}$ & $\begin{array}{c}\text { Segment } \\
\text { time }(\mathrm{s})\end{array}$ \\
\hline $\mathrm{CoSO}_{4} \cdot 7 \mathrm{H}_{2} \mathrm{O}$ & 0.15 & 1.0 & 100 \\
$\mathrm{AgNO}_{3}$ & 0.005 & 0.65 & 200 \\
$\mathrm{CH}_{3} \mathrm{COONH}_{4}$ & 0.4 & Off & Off time : 30 \\
\hline
\end{tabular}

Co and Ag: the applied potential and the deposition time. The Co layer was deposited at $1.0 \mathrm{~V}$, and the Ag layer was deposited at $0.65 \mathrm{~V}$, which is close to the upper limit for Co reduction. The times were Co: $50 \mathrm{~s}, \mathrm{Ag}: 100 \mathrm{~s}$, and off-potential time: $30 \mathrm{~s}$.

Within the nanoscale channel, an immediate change in potential within a few seconds was accompanied by problems such as charging resulting from the electric double layer and concentration unbalance of the two metal ions near to the interface of the metal deposition layer and electrolyte. Applying a stair-shape periodical potential design like that in Figure 1 effectively prevents microbubbles and over electrolyzing.

3.2. Structure Analysis. The optimized deposition conditions and program setting are given in Table 1 . The $\mathrm{Ag}$ and Co segments were deposited in the AAO template with 30 rounds. After dissolving the AAO template in $5 \% \mathrm{NaOH}$ solution for $30 \mathrm{~min}$, the nanowires were imaged, and the micrographs are shown in Figure 5. The TEM bright field image in Figure 5(a) shows a clear image contrast between two nearby segments, which represents the Ag and Co layers. The darker, shorter part was verified to contain mainly Ag. Both diffraction patterns and TEM-EDS were used to identify and confirm the composition of the segment along the nanowire axis. The multilayered nanowires were composed of two types of segments, $[\mathrm{Co}]$ and $\left[\mathrm{Ag}_{80} \mathrm{Co}_{20}\right]$, and developed a homogenous and period structure. Moreover, an indistinct interface can be clearly observed in the TEM bright image. This result can be explained by the original stage-potential design and the appearance of the $\mathrm{Co}-\mathrm{Ag}^{+}$interface redox reaction. To obtain a clear interface between the two metals, they were annealed at $200^{\circ} \mathrm{C}$ for $1 \mathrm{hr}$. Figure 5(b) shows the TEM image after annealing, revealing better and clearer segments of $\mathrm{Co}_{99.57} / \mathrm{Ag}_{100}$ multilayered nanowires.

3.3. Magnetic Analysis. For storage applications, it is interesting to compare the magnetic hysteresis loops of pure Co nanowires and $\mathrm{Ag} / \mathrm{Co}$ multilayered nanowires. The hysteresis loop measurements were performed with the magnetic field parallel and perpendicular to the nanowire axis, as shown in Figures 6(a) and 6(b), respectively. The pure Co nanowires had a $H_{c}$ of 300 Oe when the applied magnetic field was parallel to the long axis of the nanowires, compared to a $H_{c}$ of $225 \mathrm{Oe}$ with a perpendicular field. The $\mathrm{Ag} / \mathrm{Co}$ multilayer nanowires had almost the same coercivity $H_{c}$ of 210 Oe but showed obvious magnetic anisotropy and lower saturation magnetization (Ms) than the pure Co nanowires. The pure Co nanowires showed easier orientation along the axis (easy axis). However, the easy axis of the $\mathrm{Ag} / \mathrm{Co}$ multilayered 


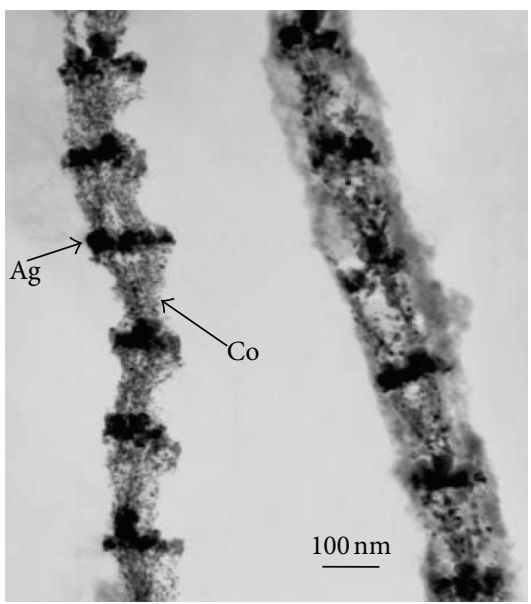

(a)

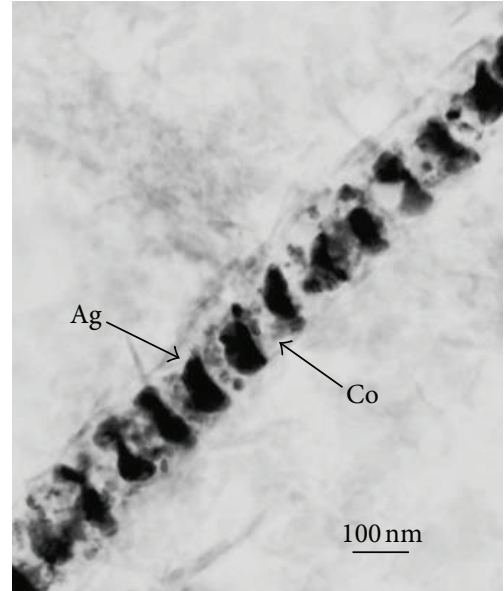

(b)

FIGURE 5: (a) TEM bright-field image of $[\mathrm{Co}] /\left[\mathrm{Ag}_{80} \mathrm{Co}_{20}\right]$ multilayered nanowires, and (b) $\mathrm{Co}_{99.57} / \mathrm{Ag}_{100}$ multilayered nanowires after annealing at $200^{\circ} \mathrm{C}$ for $1 \mathrm{~h}$.

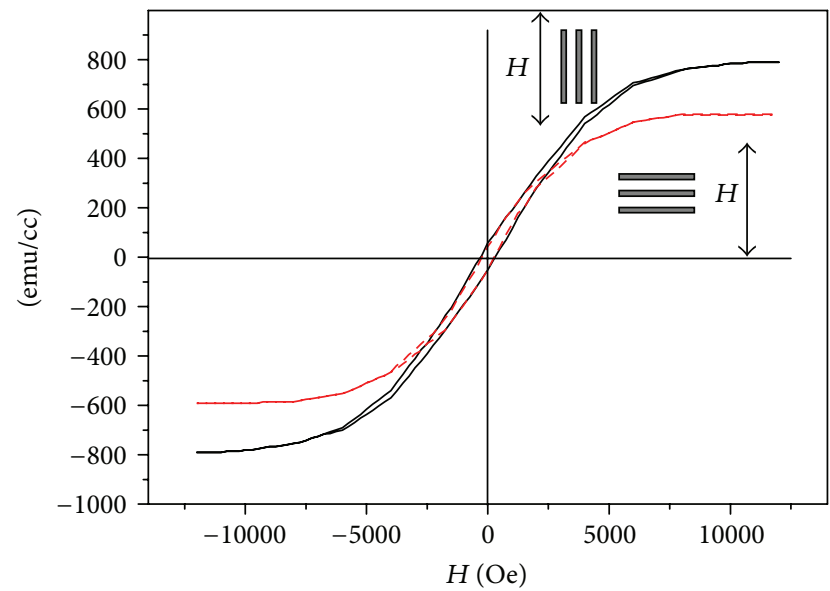

(a)

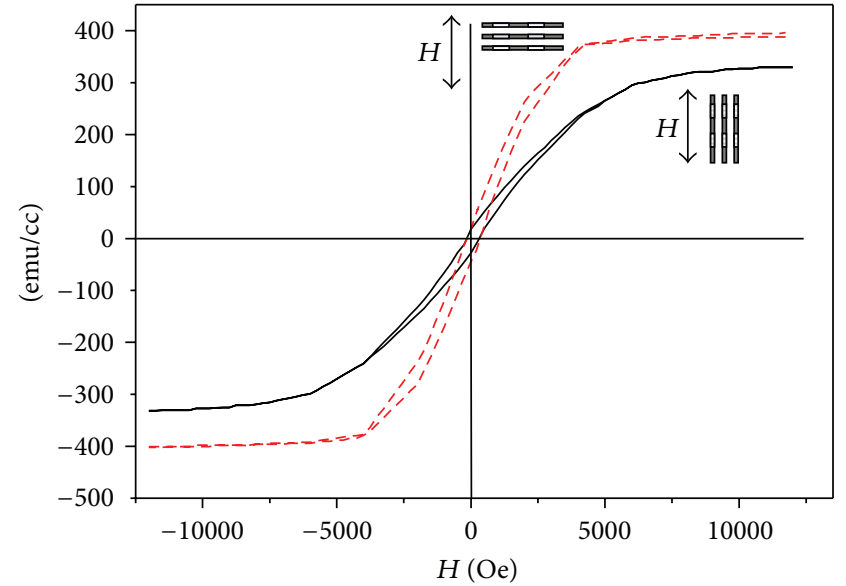

(b)

Figure 6: (a) Magnetic hysteresis of pure Co nanowires and (b) $\mathrm{Co}_{99.57} / \mathrm{Ag}_{100}$ multilayered nanowires along two vertical axes.

nanowires was oriented perpendicular to the axis of the nanowire. However, a more detailed characterization of electrodeposited $\mathrm{Ag} / \mathrm{Co}$ multilayered nanowires is required to elucidate the magnetic behavior of the nanowires.

\section{Conclusion}

In this study, electrochemical experiments and analyses were used to determine the optimized conditions to synthesize $\mathrm{Ag} / \mathrm{Co}$ multilayer nanowires that were $100 \mathrm{~nm}$ in diameter by single-bath electrodeposition using an AAO template. The segment composition of the nanowires was $[\mathrm{Co}] /\left[\mathrm{Ag}_{80} \mathrm{Co}_{20}\right]$, which was not stable or homogeneous throughout the nanowire. However, nearly pure $\mathrm{Co} / \mathrm{Ag}$ nanowires of $\mathrm{Co}_{99.57} / \mathrm{Ag}_{100}$ could be obtained by annealing, and they showed different magnetic properties compared to pure Co nanowires, such as more obvious anisotropy and a change in the easy axis.

\section{References}

[1] M. N. Baibich, J. M. Broto, A. Fert et al., "Giant magnetoresistance of (001)Fe/(001)Cr magnetic superlattices," Physical Review Letters, vol. 61, no. 21, pp. 2472-2475, 1988.

[2] T. Valet and A. Fert, "Theory of the perpendicular magnetoresistance in magnetic multilayers," Physical Review B, vol. 48, no. 10, pp. 7099-7113, 1993.

[3] L. Piraux, J. M. George, J. F. Despres et al., "Giant magnetoresistance in magnetic multilayered nanowires," Applied Physics Letters, vol. 65, no. 19, pp. 2484-2486, 1994.

[4] W. Schwarzacher and D. S. Lashmore, "Giant magnetoresistance in electrodeposited films," IEEE Transactions on Magnetics, vol. 32, no. 4, pp. 3133-3153, 1996.

[5] C. R. Martin, "Nanomaterials: a membrane-based synthetic approach,” Science, vol. 266, no. 5193, pp. 1961-1966, 1994.

[6] K. Ounadjela, R. Ferré, L. Louail et al., "Magnetization reversal in cobalt and nickel electrodeposited nanowires," Journal of Applied Physics, vol. 81, no. 8, pp. 5455-5457, 1997. 
[7] D. Aimawiawi, N. Coombs, and M. Moskovits J, "Magnetic properties of Fe deposited into anodic aluminum oxide pores as a function of particle size," Journal of Applied Physics, vol. 70, no. 8 , article 4421, 5 pages, 1991.

[8] H. Schwanbeck and U. Schmidt, "Preparation and characterization of magnetic nanostructures using filtration membranes," Electrochimica Acta, vol. 45, no. 27, pp. 4389-4398, 2000.

[9] L. Sun, C. L. Chien, and P. C. Searson, "Fabrication of nanoporous single crystal mica templates for electrochemical deposition of nanowire arrays," Journal of Materials Science, vol. 35, no. 5, pp. 1097-1103, 2000.

[10] P. Leisner, C. B. Nielsen, P. T. Tang, T. C. Dorge, and P. Moller, "Methods for electrodepositing composition-modulated alloys," Journal of Materials Processing Technology, vol. 58, no. 1, pp. 39-44, 1996.

[11] P. E. Bradley and D. Landolt, "Pulse-plating of copper-cobalt alloys," Electrochimica Acta, vol. 45, no. 7, pp. 1077-1087, 1999.

[12] A. Blondel, B. Doudin, and J.-P. Ansermet, "Comparative study of the magnetoresistance of electrodeposited $\mathrm{Co} / \mathrm{Cu}$ multilayered nanowires made by single and dual bath techniques," Journal of Magnetism and Magnetic Materials, vol. 165, no. 1-3, pp. 34-37, 1997.

[13] E. Gómez, A. Labarta, A. Llorente, and E. Vallés, "Characterisation of cobalt/copper multilayers obtained by electrodeposition," Surface and Coatings Technology, vol. 153, no. 2-3, pp. 261266, 2002.

[14] M. Tian, J. Wang, J. Kurtz, T. E. Mallouk, and M. H. W. Chan, "Electrochemical growth of single-crystal metal nanowires via a two-dimensional nucleation and growth mechanism," Nano Letters, vol. 3, no. 7, pp. 919-923, 2003.

[15] Y.-G. Guo, L.-J. Wan, C.-F. Zhu, D.-L. Yang, D.-M. Chen, and C.-L. Bai, "Ordered Ni-Cu nanowire array with enhanced coercivity," Chemistry of Materials, vol. 15, no. 3, pp. 664-667, 2003.

[16] S. Valizadeh, L. Hultman, J.-M. George, and P. Leisner, "Template synthesis of $\mathrm{Au} / \mathrm{Co}$ multilayered nanowires by electrochemical deposition," Advanced Functional Materials, vol. 12, no. 11-12, pp. 766-772, 2003.

[17] S. Valizadeh, J. M. George, P. Leisner, and L. Hultman, "Electrochemical synthesis of $\mathrm{Ag} / \mathrm{Co}$ multilayered nanowires in porous polycarbonate membranes," Thin Solid Films, vol. 402, no. 1-2, pp. 262-271, 2002.

[18] S. Kenane, E. Chainet, B. Nguyen, A. Kadri, N. Benbrahim, and J. Voiron, "Giant magnetoresistance in Co-Ag granular films prepared by electrodeposition," Electrochemistry Communications, vol. 4, no. 2, pp. 167-170, 2002.

[19] S. Valizadeh, G. Holmbom, and P. Leisner, "Electrodeposition of cobalt-silver multilayers," Surface and Coatings Technology, vol. 105, no. 3, pp. 213-217, 1998. 

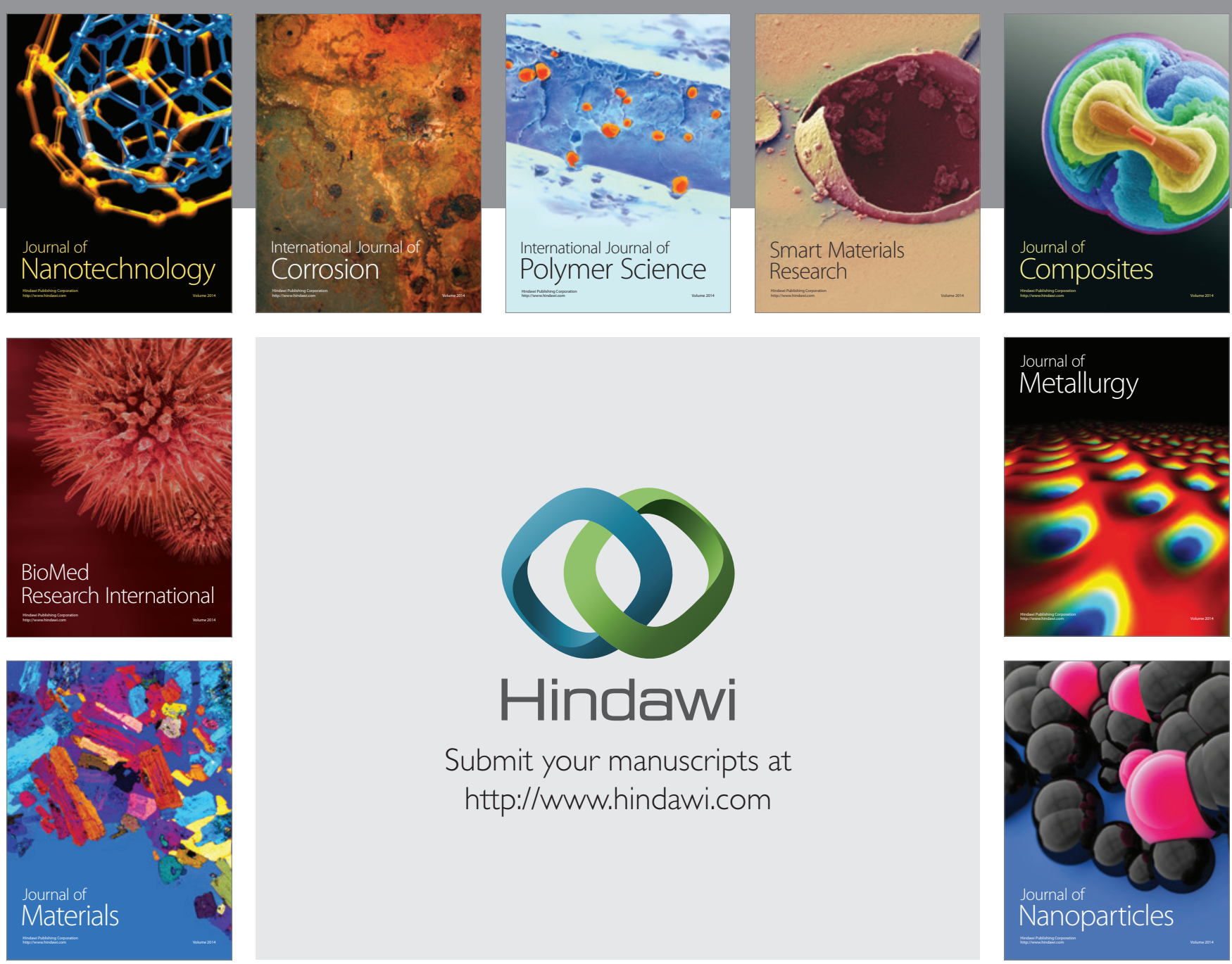

Submit your manuscripts at http://www.hindawi.com
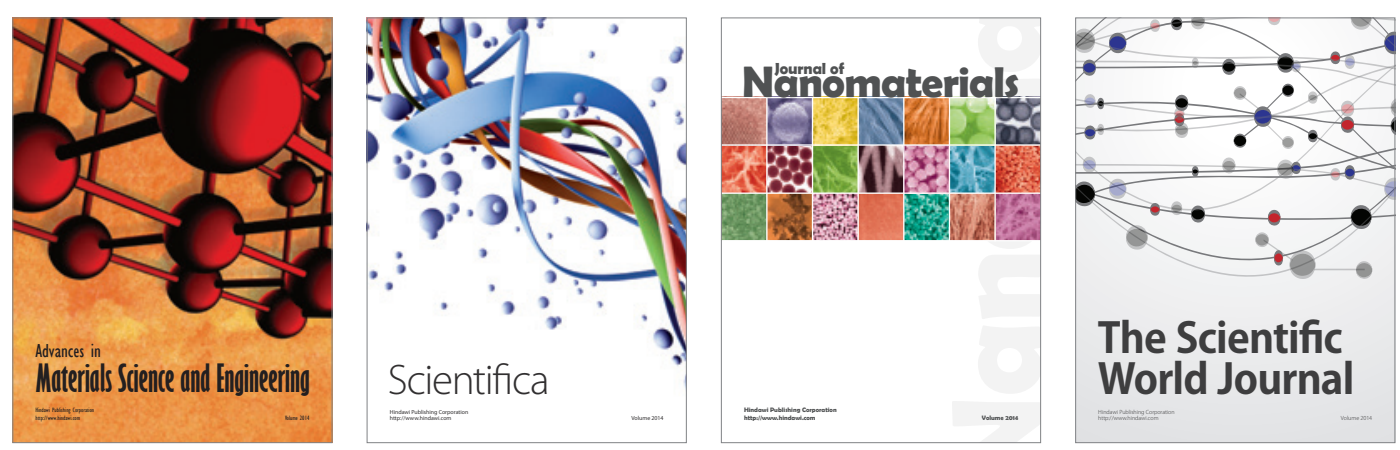

\section{The Scientific World Journal}
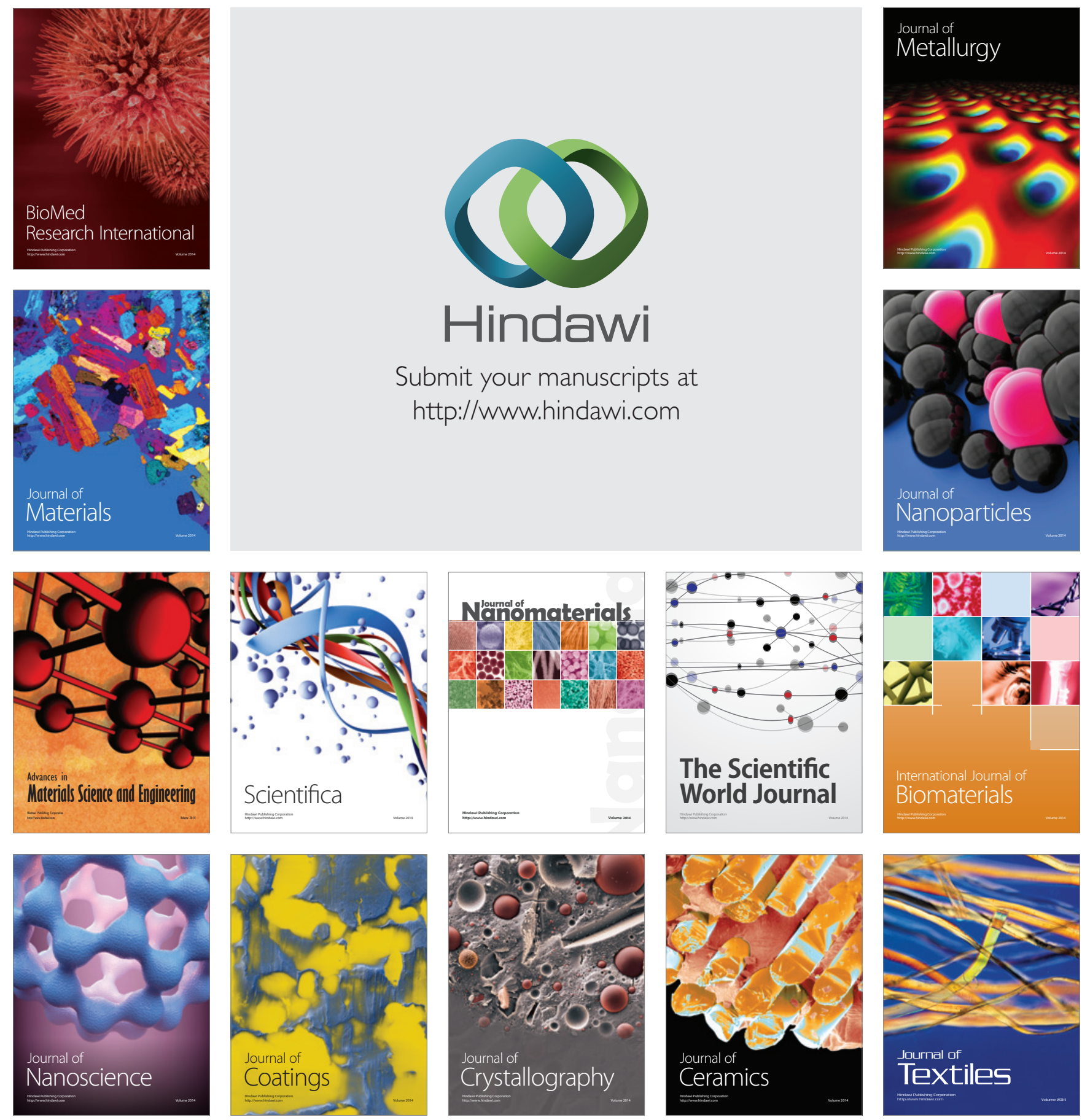